\title{
Factors Affecting Mathematics Achievement in Central Asian Specialized Universities
}

\author{
https://doi.org/10.3991/ijet.v15i19.15629 \\ Yershat Sapazhanov ${ }^{(凶)}$, Alibek Orynbassar, Shirali Kadyrov, Bakhyt Sydykhov \\ Suleyman Demirel University, Kaskelen, Kazakhstan \\ yershat.sapazhanov@sdu.edu.kz
}

\begin{abstract}
This study examines variables explaining student's academic performances in mathematics from the specialized engineering institutions. A survey consisting of 42 items was conducted from 127 students and statistical multiple regression was carried out to analyze the data set. Based on FennemaSherman Mathematic Attitude Scales followed by the result of stepwise linear regression, found a significant impact of high school geometry grades in the mathematics performance. Authors suggest that mathematics instructors in higher education should pay attention to improve their student's confidence, which in turn would decrease the anxiety level towards mathematics. The high school teachers should not advise their students to go to technical sciences in higher education unless the student's confidence and high school math grade are sufficiently high.
\end{abstract}

Keywords-Anxiety, confidence, correlations, education, stepwise regression, usefulness.

\section{Introduction}

Explaining variability of success in education is one of the most studied subject area. In education, it is very important to search for "sources of student's academic achievement" $[1,2]$. Determining the variables may help to develop better curriculum, show the ways to avoid high rate failures. Factors affecting academic performance in education has long been studied see e.g. [1] where more than one hundred variables are reviewed relevant to performance in education. As far as mathematics education is concerned, that underachievement rate is much higher as learning mathematics is complex [3, 4]. Therefore, explaining the differences becomes a major task. As reviewed in the literature section there are various research carried in this direction, however it still not satisfactory because of the complex nature of the learning. The goal of this study is to contribute to the research in this direction. Because of the cultural differences, certain factors such as socio-economic status may have different influence on performance. Similarly, factors such as admission examination scores may have distinct affects due to their variable nature according to the country. The objective is to consider various factors from the literature and include few factors of our own to analyze the variability of the academic achievement in mathematics in 
specialized engineering institutions in Kazakhstan. More specifically, we ask the following research questions:

1. How much of the variability in mathematics achievement can be explained when multiple factors are considered?

2. Which factors maximize adjusted R-squared value in multiple regression and how?

Conflict of interest statement. Authors announce that there is no conflict of interest.

\section{$2 \quad$ Literature Review}

Mathematics can be a rather challenging subject to learn. It is a well-known fact that mathematics is a difficult subject, in particular college mathematics classes such as introductory calculus. [5, 6]. For example, a study carried out in USA among 80000 students showed $27 \%$ fail rate [7]. Mathematics is considered as complex [8, $3,9]$ and as such it is important to investigate reasons and factors that explain this variability in learning mathematics. In social sciences variable or a factor is any entity that can change. Early work of Binet (1916) provided evidence that individual cognitive differences explain the variability of general educational achievement. In the last few decades many researches have been carried out to study various factors affecting the achievement in mathematics, (see e.g. $[10,11,1]$ and references therein.

Traditionally, in USA, the scores of SAT and ACT, High School GPA, IQ, and 'A' level scores are known to be important basic variables $[12,11]$. Much of the researches towards the impact of high school courses on performance in freshman mathematics has focused on predictive values of previous experiences on outcomes for students taking their first mathematical courses at the university $[13,14,15,16]$. In Kazakhstan, there is Unified National Test (UNT), which is an analog of ACT or SAT in USA. Any student who wishes to study in higher education institutions in Kazakhstan must sit for this test.

Early studies on attitude as a factor in mathematics education traced back to Dutton (1951). As a part of attitude scales, the mathematical anxiety have a negative effect when a person is asked to solve a mathematical problem [17]. In addition, distinct personal and environmental factors may bring negative attitudes that were found to be related to failing mathematics courses [18]. In the literature, one can find various techniques established to test students' attitudes towards mathematics. The most famous one is considered to be Fennema-Sherman mathematics attitudes scales (FSMAS) [19] consisting of 9 scales with 109 items which was shortened later by Mulhern \& Rae [20] into 6 scales with 51 items. Another interesting factor is the socalled self-efficacy which was identified to make positive effect on individuals in terms of "decreasing their stress, anxiety, and depression" [21]. Strategies such as time management, peer learning, and searching for help contributes to positive impact on learning, (see e.g. [11] where these three variables were among the eleven identified self-regulatory learning capacities.

Using multiple large data sources Sackett, Kuncel, Arneson, Cooper \& Waters (2009) studied the relation of Socio-Economic Status (SES), that includes parents' 
education levels, to admission test scores and GPA. SES was found to be correlated to test score with correlation coefficient 0.42 , while test scores have found to be correlated to GPA with correlation coefficient 0.35 . Surprisingly, although SES is related to GPA though the SES-test score-GPA chain with SES being a mediating factor, it failed to provide evidence to the hypothesis that SES and GPA are correlated. On the other hand, a research by Rindermann \& Ceci (2018) from 7 different countries showed that parent's education levels found to have more effect on shaping children's cognitive ability compared to their economic status. In a study of 19,487 students across China [22] the Ordinary Least Squares analysis provide an evidence that supplementary activities have positive impact on students' academic excellence. For other factors we refer to [1] which lists over one hundred important variables that are studied in relation to achievement in Higher Education such as student peerassessment, critical thinking, teacher's preparation, encouragement, helpfulness, grade goal, mastery learning, small group learning, intelligence, and gender.

Based on the literature review, the goal of this article is to understand the relationship between achievement in mathematics in higher education to the following possible factors: 1) supplementary courses during the high school, 2) level of parents' education, 3) High school math grades, 4) UNT math grades, 5) number of hours spent to prepare math classes in the university per week, 6) the language of study in high school, and 7) attitudes towards mathematics. Additionally, it is interesting to know if there is any relation of the success in mathematics to the demographic data such as the age, the language of study, type of high school and region.

\section{$3 \quad$ Method}

Sample: Data was collected among students in one male specialized university. Although this is an instance of convenience sampling, there are only five such universities available in Kazakhstan. There were a total of 127 participants. The sample was composed of over $80 \%$ of second year students at the universities. Mathematics was a compulsory subject for all the students involved. Table 1 provides the summary statistics of the sample. 
Table 1. Summary Statistics on participants

\begin{tabular}{|c|c|c|c|c|}
\hline $\begin{array}{c}\text { Language of } \\
\text { study at High } \\
\text { school }\end{array}$ & Type of the school & $\begin{array}{l}\text { Profile of the high } \\
\text { school }\end{array}$ & $\begin{array}{l}\text { Father's level of } \\
\text { education }\end{array}$ & $\begin{array}{l}\text { Mother's level of } \\
\text { education }\end{array}$ \\
\hline $\begin{array}{l}\text { Kazakh } \\
62.9 \% \\
\text { Russian } \\
23.6 \% \\
\text { Not written } \\
13.3 \%\end{array}$ & $\begin{array}{l}\text { International } \\
0.8 \% \\
\text { State } \\
40.2 \% \\
\text { Region } \\
7.9 \% \\
\text { City } \\
24.4 \% \\
\text { District } \\
22.8 \% \\
\text { Other } \\
3.9 \%\end{array}$ & $\begin{array}{l}\text { Gymnasium } \\
15.7 \% \\
\text { Lyceum } \\
11 \% \\
\text { College } \\
3.1 \% \\
\text { Specialized } \\
30.7 \% \\
\text { Technical } \\
0 \% \\
\text { Traditional } \\
38.6 \% \\
\text { Other } \\
0.8 \%\end{array}$ & $\begin{array}{l}\text { Secondary } \\
23.6 \% \\
\text { Technical/ Specialized } \\
18.9 \% \\
\text { Higher } \\
51.2 \% \\
\text { Not written } \\
6.3 \%\end{array}$ & $\begin{array}{l}\text { Secondary } \\
18.9 \% \\
\text { Technical/Specialized } \\
10.2 \% \\
\text { Higher } \\
70.0 \% \\
\text { Not written } \\
0.8 \%\end{array}$ \\
\hline
\end{tabular}

Data was collected anonymously through a survey consisting of 42 items. There are two factors are our dependent variables; 1)Two items are the semester GPA's of 2 credits Analytic geometry (AGG) course from 1st year autumn semester, and 2) 1 credit Calculus (CG) course GPA's from spring semester taken in the 1styear. Algebra and geometry GPA's from 11th grade were used to measure high school math grades. As for the UNT results, mathematics and mathematics literacy scores were included as two items. "Language of study in high school" variable is nominal, Russian or Kazakh.

In order to measure attitudes, the shortened form of FSMAS (FSMAS-SF) [20]was used in the survey. As mentioned above, FSMAS-SF has 6scales with 51 items in total. There were only 3 scales of 24 items that were considered. These were The Mathematics-Related Affect scale (MRA), The Teacher Scale (T), and The Mathematics Usefulness Scale $(\mathrm{U})$. The remaining three scales were omitted for various reasons. For example, Parents Attitudes scale was dropped because a separate factor on parents' education levels were determined, which was thought to be more important to consider. In addition, Male Domain scale was dropped as the participants consist of males only. Success scale was skipped to make the survey shorter because there were other factors involved. These 24 items were translated into Russian language to make it accessible to all the participants where students had 5 choices such as:

$$
\begin{aligned}
& 1=\text { "Strongly Disagree" } \\
& 2=\text { "Disagree" } \\
& 3=\text { "Neutral" } \\
& 4=\text { "Agree" } \\
& 5=\text { "Strongly Agree". }
\end{aligned}
$$


For this translated attitude test, reliability test was conducted. There were also three additional Likert-scale items added:

1. I am satisfied with the conditions for preparing for mathematics at the Institute

2. I know why I entered my specialty

3. This institution - was my own choice

Hence, the survey was conducted during summer of 2018 before students commence their second year.

Data analysis: To investigate the relation of success in mathematics to the variables, the statistical linear regression analysis was performed. More precisely, stepwise multiple linear regressions were run. In general, regression analysis produces unbiased predictions [23]. Then, applied regression analysis was applied to the following case:

The dependent variable $\mathrm{Y}$ is the mean of AGG and CG, but 24 items for attitudes out of 40 independent variables were grouped into 3 factors MRA, T, U as mentioned above. This resulted in 18 independent variables. Analysis of correlation matrix was performed and was reported.

\title{
4 Results
}

For the translated 24-item attitude test with three scales MRA, T, and U reliability test was administered. Cronbach's alphas for the 9-item Mathematics-Related Affect scale (MRA), 9-item Teacher scale (T), and 6-item Mathematics Usefulness scale (U) are $0.92,0.82$, and 0.70 , respectively. Moreover, the overall 24- item attitude test is found to be highly reliable with $\alpha=0.90$.

To generate results SPSS was used. Before providing finding of the stepwise regression, Pearson correlation between variables was considered with all the variables including the dependent variable. As there are many variables, the correlation matrix will not be provided except for the significant ones. Hence, the notation for the following variables were used:

\author{
$Y \frac{\text { Analytic geometry grades (1st semester) }+ \text { Calculus grades (2nd semester) }}{2}$ \\ HSGG: High school geometry grades \\ HSAG: High school algebra grades \\ UNT - math: Unified National Test mathematics component \\ MRA: Mathematics - Related Affect scale \\ T: Teacher Scale \\ U: Mathematics Usefulness Scale
}




$$
B=
$$

I am satisfied with the conditions for preparing for mathematics at the Institute

The following Table 2 provides the descriptive statistics for these variables.

Table 2. Descriptive Statistics

\begin{tabular}{|l|c|c|c|c|c|}
\hline & $\mathbf{N}$ & Minimum & Maximum & Mean & Std. Deviation \\
\hline Age & 127 & 17 & 19 & 18.7 & 0.63 \\
\hline Y & 125 & 50 & 95 & 69.93 & 14.06 \\
\hline HSGG & 123 & 3 & 5 & 4.12 & 0.65 \\
\hline HSAG & 124 & 3 & 5 & 4.11 & 0.69 \\
\hline UNT - math & 119 & 0 & 40 & 25.32 & 7.39 \\
\hline UNT - math literacy & 119 & 0 & 20 & 16.54 & 4.19 \\
\hline MRA & 120 & 1 & 5 & 3.53 & 1.03 \\
\hline T & 125 & 2.17 & 5 & 3.90 & 0.73 \\
\hline U & 120 & 1.67 & 5 & 3.94 & 0.72 \\
\hline B & 127 & 1 & 5 & 3.46 & 1.11 \\
\hline
\end{tabular}

Valid N (list wise)

Table 3 provides the correlation matrix for those variables that have significant $(p<0.05)$ correlation with the dependent variable Y.

Table 3. Correlations

\begin{tabular}{|l|c|c|c|c|c|c|c|}
\hline \multicolumn{1}{|c|}{$\mathbf{r}$} & $\mathbf{1}$ & $\mathbf{2}$ & $\mathbf{3}$ & $\mathbf{4}$ & $\mathbf{5}$ & $\mathbf{6}$ & $\mathbf{7}$ \\
\hline $\mathrm{Y}(1)$ & 1 & & & & & & \\
\hline $\mathrm{MRA}(2)$ & $.660^{* *}$ & 1 & & & & & \\
\hline T(3) & $.329^{* *}$ & $.439^{* *}$ & 1 & & & & \\
\hline U(4) & $.204^{*}$ & $.388^{* *}$ & $.360^{* *}$ & 1 & & & \\
\hline HSGG(5) & $.599^{* *}$ & $.483^{* *}$ & 0.148 & 0.165 & 1 & & \\
\hline HSAG(6) & $.554^{* *}$ & $.609^{* *}$ & $.202^{*}$ & $.280^{* *}$ & $.774^{* *}$ & 1 & \\
\hline UNT-math (7) & $.219^{*}$ & $.288^{* *}$ & 0.155 & 0.045 & $.209^{*}$ & $.194^{*}$ & 1 \\
\hline B (8) & $.492^{* *}$ & $.700^{* *}$ & $.433^{* *}$ & $.529 * *$ & $.384^{* *}$ & $.459^{* *}$ & $.251^{* *}$ \\
\hline
\end{tabular}

* Correlation is significant at the 0.05 level (2-tailed)

** Correlation is significant at the 0.01 level (2-tailed)

As the variables excluded from Table 3 have low correlation with Y, they are not expected to enter in the stepwise regression. However, this should not mean that all the variables in Table 3 will appear in the stepwise regression due to collinearity. For example, HSGG and HSAG have Pearson correlation $r=0.775(p<0.001)$ as shown in Table 1, which hints that one of them will be dropped out in the regression analysis. We see that MRA has the highest correlation with Y, $r=0.66(p<0.001)$ and it will be no surprise to see MRA entered in the regression. Indeed, Table 4 summarizes stepwise regression analysis. 
Table 4. Model Summary

\begin{tabular}{|c|c|c|c|c|c|c|c|c|c|}
\hline \multirow{2}{*}{ Model } & \multirow{2}{*}{$\mathbf{R}$} & \multirow{2}{*}{ R Square } & \multirow{2}{*}{$\begin{array}{c}\text { Adjusted R } \\
\text { Square }\end{array}$} & $\begin{array}{l}\text { Std. Error of } \\
\text { the Estimate }\end{array}$ & $\begin{array}{c}\text { R Square } \\
\text { Change }\end{array}$ & F Change & $\boldsymbol{d} \boldsymbol{f} \mathbf{1}$ & $\boldsymbol{d f 2}$ & $\begin{array}{c}\text { Sig. } \boldsymbol{F} \\
\text { Change }\end{array}$ \\
\hline 1 & $.645^{\mathrm{a}}$ & .417 & .407 & 11.28887 & .417 & 42.835 & 1 & 60 & .000 \\
\hline 2 & $.712^{\mathrm{b}}$ & .507 & .490 & 10.46488 & .090 & 10.821 & 1 & 59 & .002 \\
\hline
\end{tabular}

a. Predictors: (Constant), MRA

b. Predictors: (Constant), MRA, HSGG

In the stepwise multiple regression, we see that the MRA entered first and explained $41.7 \%$ of the variance in the mathematics achievement $(\mathrm{F} 1.60=42.83, \mathrm{p}<$ $0.001)$. Then, HSGG entered second and explained further $9 \%$ of variability $(\mathrm{F} 1.59=10.82, \mathrm{p}<0.01)$. The linear regression formula for the model is provided below

$$
Y=13.651+6.825 \cdot M R A+7.827 \cdot H S G G
$$

As we see from the regression analysis HSGG entered in all the models and explained most of the variability. However, this does not mean that High School Algebra Grades HSAG is not a significant factor. The reason why it did not enter in the stepwise regression is that it highly correlates with HSGG, in fact Pearson Correlation between HSGG and HSAG is $0.998, n=123, p<0.001$ ). It is no surprise that Mathematics-Related Affect scale, entered in the regression as it has $r=0.66, n=$ $118, p<0.001$ with $\mathrm{Y}$, the mean of analytic geometry and calculus grades from college. Another interesting result is the correlation between $\mathrm{Y}$ and Teacher scale, $\mathrm{T}$, which is $0.33, n=123, p<0.001$. Another surprising result was that 1 st semester analytic geometry grades AGG have very high correlation $r=0.93, n=123, p<$ 0.001 with 2 nd semester calculus grades CG. There is some correlation $r=$ $0.22, n=117, p<0.05$ between UNT math results and achievement in mathematics in college, Y, however it did not enter in the above models. On the other hand, geometry grades entered in the models while it has no significant correlation with $\mathrm{Y}$, $r=0.16, n=121, p>0.05$. Another correlation with $\mathrm{Y}$ is the Mathematics Usefulness Scale, $\mathrm{U}$, which is $r=0.2, n=118, p<0.05$. The last item that has significant correlation $r=0.49, n=125, p<0.001$ with $\mathrm{Y}$ is $\mathrm{B} 2$ : "I am satisfied with the conditions for preparing for mathematics at the Institute". The other variables do not seem to correlate to $\mathrm{Y}$. This was omitted to consider the correlations of $\mathrm{Y}$ to individual items from attitude scales.

\section{$5 \quad$ Discussion and Conclusion}

Learning is a complex process with many dimensions. Despite the numerous studies carried out to investigate factors affecting the learning and achievement the research in this direction will continue as far as humanity exist. The current study wished to explore which factors explain most of the variability in mathematics achievement. As such, stepwise linear regression model was used, as it is effective in detecting the most useful subset of factors that jointly explain and predict the variabil- 
ity of the dependent variable. Moreover, the model helps to see the contribution of each factor related to the previously considered factors. The following paragraphs interpret some of the significant components found in the findings and its relation to literature.

Among various factors the current study found was that MRA is the most significant predictor of the achievement in specialized university mathematics courses with strong correlation of $r=0.66$. This is the Mathematics-Related Affect scale developed by Fennema \& Sherman (1976) as two separate scales, namely Mathematics Anxiety Scale and Confidence in Learning Mathematics scale, and later shortened by Mulhern \& Rae [20] into one scale. This is consistent with [24]where the average correlation between confidence in learning and mathematics achievement in high school 9-12 grades students range between 0.22 and 0.47 . It hints that if students are confident in their ability to succeed in mathematics then indeed their chances of getting better grades increases. More precisely, from the reported formula (1) we can interpret that if the student's Mathematics-Related Affect scale is increased by one unit, then their mathematics grade will be increased by $6.825 \%$. Moreover, as the adjusted $\mathrm{R}$ square for the simple linear regression model with one factor (MRA) is 0.407 , we may interpret that the student's confidence level alone can explain about $40.7 \%$ of the variability. This suggests that educators should do activities related to increase students' attitudes towards mathematics. However, we note that we have not tried to find out a causal relation is between the attitudes towards mathematics and achievement, which may be another interesting future research direction.

The remaining two attitude scales, Teacher Scale and Usefulness Scale did not enter in the stepwise regression model. They both have positive correlations with the achievement, but weaker than MRA Scale. This is consistent with the report of Fennema \& Sherman [24]. This implies more than simple correlation, namely, these two factors have nothing significant to add in addition to MRA scale in explaining the variability in mathematics achievement. While [24] developed the Teacher Scale to estimate "student' perceptions of their teacher's attitude towards them as learners of mathematics", their Usefulness Scale measures students' attitudes on usefulness of mathematics. This provides correlation analysis that both Teacher Scale and Usefulness Scale are uncorrelated with high school geometry grades, the other predicting factor of the achievement in the model (1).

Not all items from [20] attitude scales were used as that would make the questionnaire lengthy and some of the items thought to be not very relevant to the context. For the future study, all the items may be considered and adopted questionnaire can be conducted from a larger sample size and from multiple institutions. Another future direction is to run the factor analysis of the translated items from the attitude test to obtain a new attitude construct more suitable to Kazakhstan.

This is not much about achievement and besides, the teacher student relation in the college is not as strong as in the high school. It is not clear why Usefulness scale was not effective. One reason might be that in specialized university, area of specialization are determined at the end of the second year while the students in this study were only starting their second year and as a result, they are not sure if the math courses they are taking is useful and whether math will help them in these tracks. In addition, the area 
of specialization is determined at the end of the 2 nd year by an examination committee who do not see mathematics a crucial subject.

It can be noted that high school geometry grades entered second in the regression and explained further $9 \%$ of the variance. Moreover, from formula (1) it is obvious that one unit increase in high school geometry grades increases the university mathematics grade by $7.827 \%$. The regression model can explain about $49 \%$ of achievement variability and the remaining $51 \%$ probably depends on other factors that are not considered in this article. Another possible research direction could be if there is a better linear regression model that includes some subgroup of variables that we considered with adjusted R squared improved.

It is surprising to find out the correlation between mathematics test scores of unified national test and high school math grades is low. The same applies to the correlation between the same test scores and university math grades. It may be that unified national test on mathematics subject is not measuring students' mathematics skills well, but this requires further research in this direction. UNT is only the first stage and there are three more stages to enter the specialized institution.

The other variables, including parents' education level, school type, language of study at high school, and time spent for preparation on mathematics courses have no strong correlations with mathematics achievement.

In conclusion, this research is carried out to study how certain factors explain the variability of mathematics achievement. To this end, we conducted a questionnaire of 42 items from 127 students of one local specialized institution. Our findings suggest that there are two factors that influence students' mathematics, which is related to affect scale (confidence and anxiety) and their high school mathematics achievements are two main predictors of achievement in university mathematics courses. If teachers want their students to be successful in technical sciences, they should try to improve students' math grades together with their confidence in mathematics.

\section{References}

[1] M. Schneider and F. Preckel, "Variables associated with achievement in higher education: A systematic review of meta-analyses," Psychological Bulletin, vol. 143, no. 6, pp. 565600, 2017. https://doi.org/10.1037/bul0000098

[2] P. C. Lin, H. K. Lu and S. M. Fan, "Exploring the Impact of Perceived Teaching Style on Behavioral Intention toward Moodle Reading System," International Journal of Emerging Technologies in Learning, vol. 9, no. 3, 2014. https://doi.org/10.3991/ijet.v9i3.3500

[3] A. Gutiérrez and P. Boero, Handbook of research on the psychology of mathematics education: Past, present and future, Sense publishers, 2006.

[4] A. Drigas and M. Pappas, "Online and other game-based learning for mathematics," International Journal of Online and Biomedical Engineering, vol. 11, no. 4, pp. 62-67, 2015.

[5] M. Oehrtman, M. Carlson and P. W. Thompson, "Foundational reasoning abilities that promote coherence in students' function understanding.," Making the connection: Research and teaching in undergraduate mathematics education, vol. 27, p. 42, 2008. https:// doi.org/10.5948/upo9780883859759.004

[6] D. Tall, "Students' difficulties in calculus," In proceedings of working group, vol. 3, pp. 13-28, 1993. 
[7] D. M. Bressoud, M. P. Carlson, V. Mesa and C. Rasmussen, "The calculus student: insights from the Mathematical Association of America national study," International Journal of Mathematical Education in Science and Technology, vol. 44, no. 4, p. 685-698, 2013. https://doi.org/10.1080/0020739x.2013.798874

[8] A. J. Bishop, K. Clements, C. Keitel, J. Kilpatrick and C. Laborde, International handbook book of mathematics education, Dordrech, The Netherlands: Kluwer, 1996. https://doi.org/ 10.1007/978-94-009-1465-0

[9] I. Musabirov, S. Pozdniakov and K. Tenisheva, "Predictors of academic achievement in blended learning: The case of data science minor," International Journal of Emerging Technologies in Learning, vol. 15, no. 5, pp. 64-74, 2019. https://doi.org/10.3991/ijet.v14 i05.9512

[10] K. Singh, M. Granville and S. Dika, "Mathematics and science achievement: Effects of motivation, interest, and academic engagement.," The Journal of Educational Research, vol. 95, no. 6, pp. 323-332, 2002. https://doi.org/10.1080/00220670209596607

[11] M. Richardson, C. Abraham and R. Bond, "Psychological correlates of university students' academic performance: A systematic review and meta-analysis.," Psychological Bulletin, vol. 138, no. 2, pp. 353-387, 2012. https://doi.org/10.1037/a0026838

[12] B. Bridgeman, J. Pollack and N. Burton, "Understanding what SAT Reasoning Test ${ }^{\mathrm{TM}}$ scores add to high school grades: A straightforward approach," ETS Research Report Series, vol. 2, pp. i-20, 2004. https://doi.org/10.1002/j.2333-8504.2004.tb01967.x

[13] J. D. Austin, "High school calculus and first-quarter college calculus grades," Journal for Research in Mathematics Education, vol. 10, no. 1, p. 69-72, 1979. https://doi.org/10.23 $\underline{07 / 748747}$

[14] M. B. Burton, "The effect of prior calculus experience on "introductory" college calculus," The American Mathematical Monthly, vol. 96, no. 4, p. 350-354, 1989. https://doi.org/10. $\underline{2307 / 2324093}$

[15] P. Wilhite, B. Windham and R. Munday, "Predictive effects of high school calculus and other variables on achievement in a first-semester college calculus course," College Student Journal, vol. 32, no. 4, pp. 610-618, 1998.

[16] B. D. S. Sydykhov, M. Muratbekova, Z. Issayeva, M. Burkitbayeva, M. Kavakli and L. Rizayeva, "Methodology for the Development of Search and Research Skills of Prospective Math Teachers in a Course on Mathematical Physics Equations," EURASIA Journal of Mathematics, Science and Technology Education, vol. 13, no. 11, 2017. https://doi.org/ 10.12973/ejmste/79047

[17] F. C. Richardson and R. M. Suinn, "The mathematics anxiety rating scale: Psychometric data," Journal of Counseling Psychology, vol. 19, pp. 551-554, 1972. https://doi.org/10.10 $\underline{37 / \mathrm{h} 0033456}$

[18] I. M. G. Chacón, "La alfabetización emocional en educación matemática: Actitudes, emociones y creencias," Uno: Revista de didáctica de las matematicas, vol. 13, pp. 7-22, 1997.

[19] E. Fennema and J. A. Sherman, "Fennema-Sherman mathematics attitudes scales: Instruments designed to measure attitudes toward the learning of mathematics by females and males," Journal for research in Mathematics Education, vol. 7, no. 5, pp. 324-326, 1976. https://doi.org/10.2307/748467

[20] F. Mulhern and G. Rae, "Development of a shortened form of the Fennema-Sherman Mathematics Attitudes Scales," Educational and psychological Measurement, vol. 58, no. 2, pp. 295-306, 1998. https://doi.org/10.1177/0013164498058002012

[21] R. M. Klassen and E. L. Usher, " Self-efficacy in educational settings: Recent research and emerging directions," In The decade ahead: Theoretical perspectives on motivation and achievement, pp. 1-33, 2010. https://doi.org/10.1108/s0749-7423(2010)000016a004 
[22] S. Jiang, "he Relationship between Chinese Secondary Students' School Performance and the Total Hours of Their Doing Extra-Curricular Activities," 2018.

[23] A. S. Goldberger, "Statistical Inference in the Great IQ Debate," in Third World Congress of the Econometric Society, Toronto, Canada., 1975.

[24] E. Fennema and J. Sherman, "Sex-related differences in mathematics achievement, spatial visualization and affective factors," American educational research journal, vol. 14, no. 1, pp. 51-71, 1977. https://doi.org/10.3102/00028312014001051

\section{$7 \quad$ Authors}

Yershat Sapazhanov Suleyman Demirel University, Faculty of Education and Humanities, Department of Pedagogical Mathematics and Natural Science - Senior Lecturer, Kazakhstan, Kaskelen, Ablaykhan 1.

Alibek Orynbassar Suleyman Demirel University, Faculty of Education and Humanities, Department of Pedagogical Mathematics and Natural Science - Senior Lecturer, Kazakhstan, Kaskelen, Ablaykhan 1.

Shirali Kadyrov Suleyman Demirel University, Faculty of Engineering and Natural sciences, Department of Mathematics and Natural Sciences - Assoc. Prof, Kazakhstan, Kaskelen, Ablaykhan 1.

Bakhyt Sydykhov Suleyman Demirel University,Faculty of Education and $\mathrm{Hu}-$ manities, Department of Pedagogical Mathematics and Natural Science - Assoc. Prof, Kazakhstan, Kaskelen, Ablaykhan 1.

Article submitted 2020-05-17. Resubmitted 2020-06-20. Final acceptance 2020-06-21. Final version published as submitted by the authors. 